\title{
Comparison of Microscopic Endodontic Techniques: A Systematic Review and Meta-Analysis
}

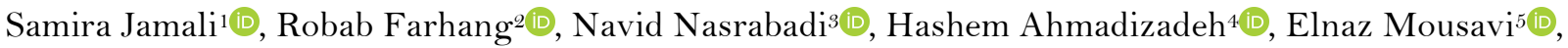 \\ Mehrzad Kavianiø@)
}

\begin{abstract}
'Department of Endodontics, Stomatological Hospital, College of Stomatology, Xi'an Jiaotong University, Shaanxi 710004, PR China. ${ }^{2}$ Department of Endodontics, Faculty of Dentistry, Ardabil University of Medical Sciences, Ardabil, Iran.

${ }^{3}$ Department of Endodontics, School of Dentistry, Shahid Beheshti University of Medical Sciences, Tehran, Iran.

${ }^{4}$ Tehran University of Medical Sciences, Tehran, Iran.

${ }^{5}$ Dental Sciences Research Center, Department of Endodontics, School of Dentistry, Guilan University of Medical Sciences, Rasht, Iran.

${ }^{6}$ Department of Oral and Maxillofacial Surgery, School of Dentistry, Tehran University of Medical Sciences, Tehran, Iran.
\end{abstract}

Correspondence: Samira Jamali, Department of Endodontics, Stomatological Hospital, College of Medicine, Xi'an Jiaotong University, Shaanxi 710004, PR China. E-mail: samira.jamali90@yahoo.com

Academic Editor: Alessandro Leite Cavalcanti

Received: 29 January 2020 / Review: 17 October 2020 / Accepted: 13 January 2021

\begin{abstract}
How to cite: Jamali S, Farhang R, Nasrabadi N, Ahmadizadeh H, Mousavi E, Kaviani M. Comparison of microscopic endodontic techniques: a systematic review and meta-analysis. Pesqui Bras Odontopediatria Clín Integr. $2021 ; 21: \mathrm{e} 5414$. https://doi.org/10.1590/pboci.2021.086
\end{abstract}

\begin{abstract}
Objective: To evaluate the success rates of resin-based endodontic surgery (RES) and endodontic microsurgery (EMS), and compare their results. Material and Methods: A total of 19 and 34 full-text papers were reviewed, and finally, 2 and 6 studies were selected for RES and EMS, respectively. The stages of the study selection process were illustrated in Figure 1. The demographic characteristics were also described using the IBM SPSS Software, and the meta-analysis was fulfilled via Stata V.14. Results: A total number of 811 teeth were analyzed in this systematic review and meta-analysis, with a mean follow-up of 38.63 months. Besides, the results of the meta-analysis indicated that both methods not only differed in terms of implementation but also produced varying outcomes. Accordingly, EMS demonstrated a higher success rate likelihood with a significant difference from that of RES. Conclusion: An excellent proof was made available through this meta-analysis regarding the resin-based endodontic surgery success rate likelihood (79.9\%) and an update for the endodontic microsurgery success rate possibility (100\%).

Keywords: Endodontics; Microscopy; Root Canal Filling Materials.
\end{abstract}




\section{Introduction}

To save a tooth, apical or endodontic surgery, as a traditional one, is considered as the last resort, which has often failed following the initial treatment of root canal and endodontic reproduction. As a clinical technique utilized by both oral surgeons and endodontists, it does not have the best reputation, which is largely due to numerous changes in techniques used over decades.

For endodontists, apical surgery is now the most advanced method for endodontic microscopy. The endodontic microscope containing triple high magnification, root ultrasonic preparation, and biocompatible filling materials was introduced in the 1990s and has been established over the past decades [1-3].

Many deficiencies in earlier methods have also been clarified following the increasing usage of surgical operating microscope in endodontic surgery. A new microsurgical epoch in surgical endodontics has been commenced parallel to microsurgical devices and new root-end filling materials with much more biological acceptance. As a minimal invasion procedure, endodontic microsurgery leads to lower pain and edema and earlier wound recovery postoperatively. This technique comes with a significant higher success rate than the traditional apical surgery method [4].

In the course of years, the inclusion of cutting-edge technology in microsurgery has also led to the progression of endodontic techniques. As a surgical practice, endodontic microsurgery employs a modern functional microscope and special microsurgical equipment. Furthermore, increased magnification and lighting on the microscope and other instruments can improve visibility, leading to better diagnostic capabilities and precision during a surgical procedure. With the use of endodontic microsurgery, the long-term prognosis of overall dental health has greatly improved.

In addition, recovery time and post-surgical trauma have diminished [5]. The use of mid-range magnification $[6,7]$ is also suggested by the endodontic microsurgery instruction for most operative methods such as hemostasis, elimination of granulation tissue, detection of root tips, apicoectomy, root-end preparation, as well as root-end filling [3].

Moreover, high magnifications [7,8] need to be applied for inspecting and documenting resected root surface, root-end cavity, and root-end filling, allowing the visualization of minute anatomic details such as accessory canals, fins, microfractures, or lateral canals [3].

Microsurgical techniques such as high-power magnification - Endodontic Microsurgery (EMS) are strictly employed by some investigations. Additionally, microsurgical equipment, ultrasonic root-end preparation, and similar biocompatible filling materials are used by others on the outcome of endodontic surgery while utilizing none or solely low-range magnification. Accordingly, the emerging question is that whether or not a high-power magnification can be critically used as a lone factor in the case of applying all other microsurgical practices, but only with the use of loupes or magnification equipment [3,9].

The purpose of the present systematic review and meta-analysis was to evaluate Resin-Based Endodontic Surgery (RES) and Endodontic Microsurgery (EMS) success rates and compare their results.

\section{Material and Methods}

A total number of 8 selected investigations were evaluated systematically to formulate the study procedure. Data extraction forms were also prepared after primary findings of searching were obtained. 
The search was carried out between 2005 and 2019. The databases searched for this purpose were Medline (Medical Literature Analysis and Retrieval System Online), PubMed, Cochrane Library, Embase, Web of Science, and Google scholar. The present study initially conducted a review of the papers' abstracts followed by a selection of investigations that were highly coordinated with the study objectives. After examining the whole text, the final selection led to eight investigations.

The following inclusion criteria were adopted: 1) Clinical trials on root-end surgery; 2) Known sample size; 3) A minimal follow-up duration of 1 year; 4) Assessment of success and failure; 5) Assessment of success and failure for each tooth; and 6) Studies limited to humans.

Regarding the exclusion criteria, the following parameters were established: 1) No evaluation of the results of root-end surgery by a study; 2) Studies with no sample size data; 3) Surgery after previous endodontic practice; 4) A follow-up period of below one year; 5) No assessment of the results based on the previous definition of the success and failure criteria.

\section{Data Extraction}

A total of 19 full-text studies on RES and 34 investigations on EMS were reviewed, and finally, eight papers were selected. The stages of the study selection process were illustrated in Figure 1.

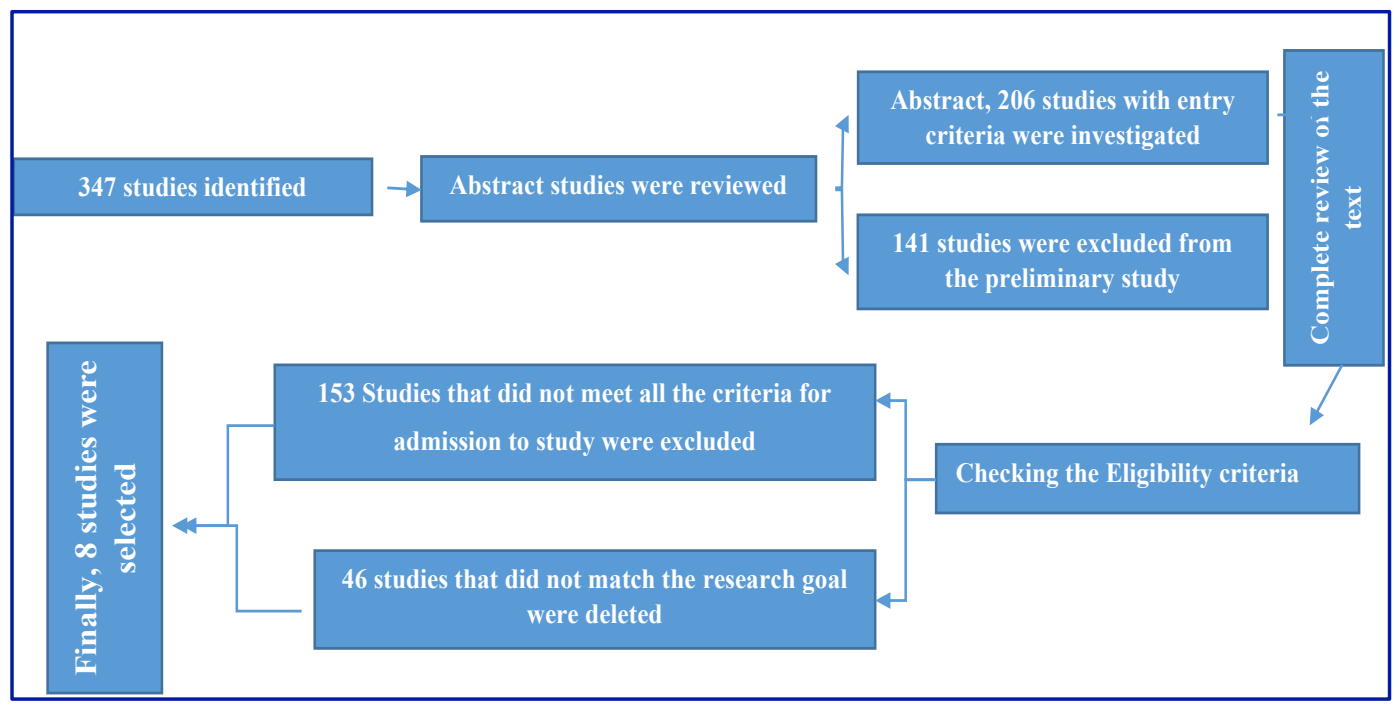

Figure 1. Study attrition diagram.

Statistical Analysis

The demographic characteristics were described using the SPSS Statistics Software, version 24 (IBM Corp., Armonk, NY, USA), and the meta-analysis was fulfilled via Stata V.14 (Stata Corp LLC., Texas, USA).

\section{Results}

Eight papers were selected, 6 for EMS [6,10-14] and 2 for RES [7,15]. A total number of 811 teeth were analyzed in this systematic review and meta-analysis, with a mean follow-up of 38.63 months. The highest success rate of the teeth was $100 \%$ [11], and the least one was by $91 \%$ [6] (Table 1). The results of the meta-analysis also indicated that both methods not only differed in terms of implementation but also produced varying outcomes. The EMS demonstrated a higher success rate likelihood with a significant difference from that of RES (Table 2 and Figure 2). 
Table1. Studies included in the meta-analysis.

\begin{tabular}{|c|c|c|c|c|c|c|c|c|}
\hline Study & Group & $\begin{array}{l}\text { Sample } \\
\text { Size }\end{array}$ & Follow-up & Magnification & Success & Failure & $\begin{array}{c}\text { Reported } \\
\text { Success } \\
\text { Rate (\%) }\end{array}$ & Study Design \\
\hline Taschieri et al. [6] & EMS & 100 & 24 & $\begin{array}{l}\text { Endoscope/ } \\
\text { Microscope }\end{array}$ & 91 & 9 & 91.0 & $\begin{array}{c}\text { Randomized Clinical } \\
\text { Trial }\end{array}$ \\
\hline Song et al. [10] & EMS & 115 & $48-96$ & Microscope & 105 & 10 & 91.3 & Retrospective Case Study \\
\hline Christiansen et al. [ $\left[\begin{array}{ll}1 & 1\end{array}\right]$ & EMS & 25 & 12 & Microscope & 25 & 0 & 100.0 & $\begin{array}{l}\text { Prospective study with } \\
\text { concurrent controls } \\
\text { randomized clinical trial }\end{array}$ \\
\hline Kim et al. [12] & EMS & 148 & $12-48$ & Microscope & 141 & 7 & 95.2 & $\begin{array}{l}\text { Prospective study with } \\
\text { concurrent controls }\end{array}$ \\
\hline Shinbori et al. [13] & EMS & 113 & 12 & $\begin{array}{l}\text { Operating } \\
\text { Microscope }\end{array}$ & 104 & 9 & 92.0 & $\begin{array}{l}\text { Clinical records and } \\
\text { periapical radiographs }\end{array}$ \\
\hline Zhou et al. [14] & EMS & 87 & 12 & Microscope & 81 & 6 & 93.1 & $\begin{array}{l}\text { Prospective Randomized } \\
\text { Controlled Study }\end{array}$ \\
\hline von Arx et al. [15] & RES & 149 & 119 & Microscope & 119 & 30 & 79.9 & $\begin{array}{c}\text { Nonrandomized } \\
\text { Prospective Clinical Trial }\end{array}$ \\
\hline Wang et al. [7] & RES & 74 & $12-30$ & Microscope & 67 & 7 & 70.5 & Prospective Cohort Study \\
\hline
\end{tabular}

EMS: Endodontic Microsurgery; RES: Resin-Based Endodontic Surgery.

Table 2. Weighted pooled success rates and individual study weights for groups RES and EMS.

\begin{tabular}{ccccc}
\hline ID & Study & \multicolumn{2}{c}{$[\mathbf{9 5 \%}$ Conf. Interval] } & \% Weight \\
& & Upper & Lower & \\
\hline 1 & Song et al. [10] & 179.945 & -177.945 & 12.45 \\
2 & Christiansen et al. [11] & 197.996 & -193.996 & 10.38 \\
3 & Kim et al. [12] & 189.589 & -183.589 & 11.45 \\
4 & Taschieri et al. [6] & 182.357 & -174.357 & 12.54 \\
5 & Shinbori et al. [13] & 185.317 & -175.317 & 12.26 \\
6 & Zhou et al. [14] & 188.473 & -176.473 & 11.98 \\
7 & von Arx et al. [15] & 163.601 & -149.601 & 16.26 \\
8 & Wang et al. [7] & 185.377 & -169.337 & 12.67 \\
\hline
\end{tabular}

EMS: Endodontic Microsurgery; RES: Resin-Based Endodontic Surgery; Heterogeneity chi-squared $=0.01$ (d.f. $=7$ ) p $=1.000$; I-squared (variation in ES attributable to heterogeneity) $=0.0 \%$; Test of ES=0: $\mathrm{z}=0.14 \mathrm{p}=0.885$.

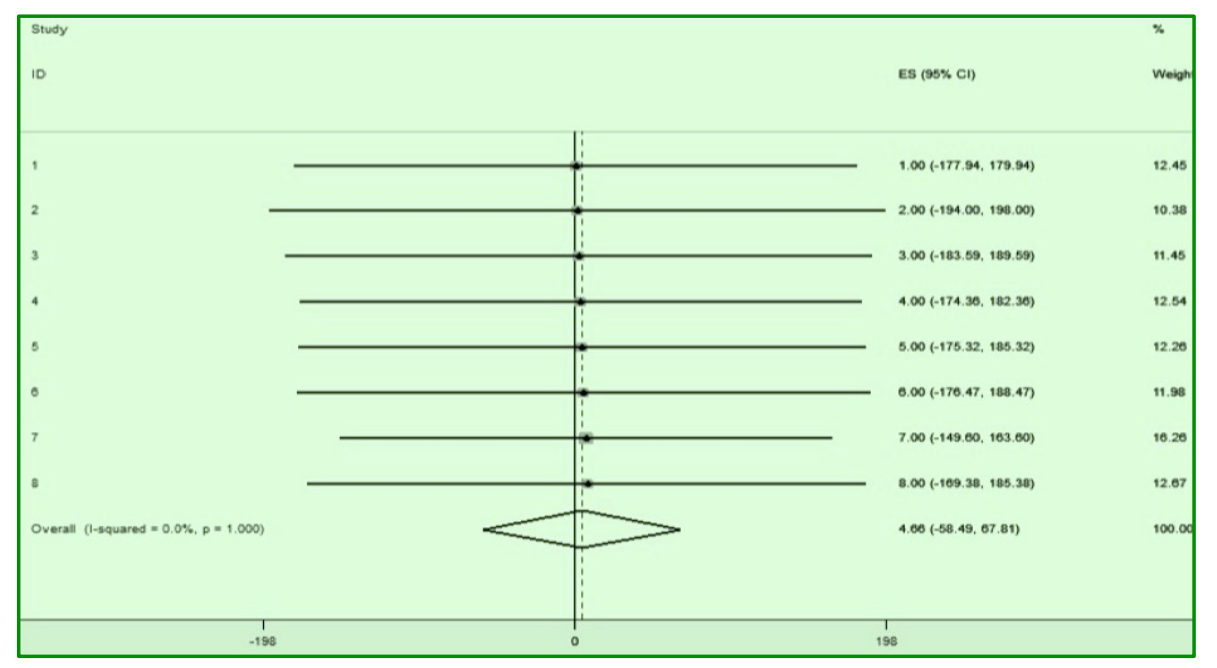

Figure 2. Weighted pooled success rates and individual study weights for groups RES and EMS.

\section{Discussion}

This study's findings revealed the rejection of the first hypothesis concerning no statistical difference in the results of up-to-date RES compared with EMS. The two methods were distinctly different, possibly explaining their varying outcomes. A report by Rud et al. [16] in this domain suggested that the given 
technique had a great success rate $(92 \%)$ following the assessment of 834 roots of molars during six months to 12.5 years. Jensen et al. [8] also used Retro last and found a 73\% success rate. Moreover, they justified this to be possible due to the method's technical complexity, which might potentialize iatrogenic errors in case of incorrect implementation of the technique.

On the other hand, von Arx et al. [15] conducted a nonrandomized prospective clinical trial, in which the whole 353 surgeries were executed by a qualified surgeon alone. Even so, a 1-year follow-up showed significant superiority of EMS techniques using MTA as the root filling material with a positive result of 91.3\% compared with RES fulfilled via Retro last (only 79.5\%). It should be noted that evidence-based medicine or dentistry usually provides the uppermost amounts of proofs to compare developed techniques and outcomes with novel methods or differences. For separate investigations, the greatest amount of proof is considered in trials with randomized control with adequate power that have lost minimum follow-up attempts. Nonetheless, such investigations are still challenging as they recruit plenty of subjects or fail to monitor all sample populations during prolonged periods recommended for such studies.

In this regard, Song et al. [10] detected that clinical outcomes following endodontic microsurgery were not significantly different after comparison of 1-year follow-up periods with lengthier durations. Christiansen et al. [11] also presented evidence on the significance of a root-end filling placement following root-end resection. Treatment of teeth by MTA similarly yielded a better significant remedy (96\%) than those treated with only smoothing of the orthograde GP root filling (52\%), with successful healing of 91 (91\%) teeth during a 2-year follow-up. A 90\% successful remedy was also obtained in the subjects used as an endoscope, whereas a success rate of $92 \%$ was documented for the group applied as a microscope in Taschieri et al. [6]. The successful outcome for isolated endodontic lesions was reported by 95.2\% in Kim et al. [12]. The inclusion criteria were fulfilled by 94 patients with 113 teeth, and they were included in a study by Shinbori et al. [13], with a total success rate of $92.0 \%$. In two meta-analyses of the literature review, the results showed that EMS's success rate was significantly greater than the probability for CRS's success rate. Besides, EMS demonstrated to have a statistically higher success rate probability than that of RES. The results of these two investigations were consistent with the findings of the present study.

\section{Conclusion}

An excellent proof was made available through this meta-analysis regarding the resin-based endodontic surgery success rate likelihood $(79.9 \%)$ and an update for the endodontic microsurgery success rate possibility (100\%). The endodontic microsurgery demonstrated to have a statistically higher success rate likelihood than that of resin-based endodontic surgery.

\section{Authors' Contributions}

\begin{tabular}{|c|c|c|}
\hline SJ & (iD) https://orcid.org/0000-0003-3803-1235 & $\begin{array}{l}\text { Conceptualization, Methodology, Formal Analysis, Investigation, Writing - Original Draft } \\
\text { Preparation, Writing - Review and Editing and Supervision. }\end{array}$ \\
\hline $\mathrm{RF}$ & https://orcid.org/0000-0003-2415-4074 & Formal Analysis, Investigation and Writing - Review and Editing. \\
\hline $\mathrm{NN}$ & https://orcid.org/0000-0002-6365-6619 & Investigation and Writing - Review and Editing. \\
\hline $\mathrm{HA}$ & (iD) https://orcid.org/0000-0001-7845-2638 & Writing - Review and Editing. \\
\hline $\mathrm{EM}$ & (iD) https://orcid.org/0000-0001-9442-5509 & Formal Analysis and Writing - Review and Editing. \\
\hline MK & (iD) https://orcid.org/0000-0002-7207-168X & Writing - Review and Editing. \\
\hline
\end{tabular}

\section{Financial Support}

None. 


\section{Conflict of Interest}

The authors declare no conflicts of interest.

\section{Data Availability}

The data used to support the findings of this study can be made available upon request to the corresponding author.

\section{References}

[1] Setzer FC. Endodontic microsurgery - A technique for the 21 st century. J Orofac Sci 2018; $10(1): 1-2$.

[2] Rubinstein RA, Kim S. Short-term observation of the results of endodontic surgery with the use of a surgical operation microscope and Super-EBA as root-end filling material. J Endod 1999; 25(1):43-8. https://doi.org/10.1016/So099-2399(99)80398-7

[3] Kim S, Kratchman S. Modern endodontic surgery concepts and practice: a review. J Endod 2006; 32(7):601-23. https://doi.org/10.1016/j.joen.2005.12.010

[4] Floratos S, Kim S. Modern endodontic microsurgery concepts: a clinical update. Dent Clin North Am 2017; 61(1):8191. https://doi.org/10.1016/j.cden.2016.08.007

[5] Wang M, Ren X, Pan Y. Micro-computed tomography-based anatomical study of the branch canals in mandibular anterior teeth in a Chinese population. Clin Oral Investig 2019; 23(1):81-86.

https://doi.org/10.1007/s00784-018-2409-y

[6] Taschieri S, Del Fabbro M, Testori T, Weinstein R. Microscope versus endoscope in root-end management: a randomized controlled study. Int J Oral Maxillofac Surg 2008; 37(11):1022-6. https://doi.org/10.1016/j.ijom.2008.07.001

[7] Wang Z-H, Zhang M-M, Wang J, Jiang L, Liang Y-H. Outcomes of endodontic microsurgery using a microscope and mineral trioxide aggregate: a prospective cohort study. J Endod 2017; 43(5):694-8. https://doi.org/10.1016/j.joen.2016.12.015

[8] Jensen S, Nattestad A, Egdø P, Sewerin I, Munksgaard E, Schou S. A prospective, randomized, comparative clinical study of resin composite and glass ionomer cement for retrograde root filling. Clin Oral Investig 2002; 6(4):236-43. https://doi.org/10.1007/s00784-002-0172-5

[9] Tsesis I, Faivishevsky V, Kfir A, Rosen E. Outcome of surgical endodontic treatment performed by a modern technique: a meta-analysis of literature. J Endod 2009; 35(11):1505-11. https://doi.org/10.1016/j.joen.2009.07.025

[10] Song M, Nam T, Shin S-J, Kim E. Comparison of clinical outcomes of endodontic microsurgery: 1 year versus longterm follow-up. J Endod 2014; 4O(4):490-4. https://doi.org/10.1016/j.joen.2013.10.034

[11] Christiansen R, Kirkevang LL, Hørsted-Bindslev P, Wenzel A. Randomized clinical trial of root-end resection followed by root-end filling with mineral trioxide aggregate or smoothing of the orthograde gutta-percha root filling-1-year follow-up. Int Endod J 2009; 42(2):105-14. https://doi.org/10.1111/j.1365-2591.2008.01474.x

[12] Kim E, Song J-S, Jung I-Y, Lee S-J, Kim S. Prospective clinical study evaluating endodontic microsurgery outcomes for cases with lesions of endodontic origin compared with cases with lesions of combined periodontal-endodontic origin. J Endod 2008; 34(5):546-51. https://doi.org/10.1016/j.joen.2008.01.023

[13] Shinbori N, Grama AM, Patel Y, Woodmansey K, He J. Clinical outcome of endodontic microsurgery that uses EndoSequence BC root repair material as the root-end filling material. J Endod 2015; 41(5):607-12. https://doi.org/10.1016/j.joen.2014.12.028

[14] Zhou W, Zheng Q, Tan X, Song D, Zhang L, Huang D. Comparison of mineral trioxide aggregate and iRoot BP plus root repair material as root-end filling materials in endodontic microsurgery: a prospective randomized controlled study. J Endod 2017; 43(1):1-6. https://doi.org/10.1016/j.joen.2016.10.010

[15] von Arx T, Hänni S, Jensen SS. Clinical results with two different methods of root-end preparation and filling in apical surgery: mineral trioxide aggregate and adhesive resin composite. J Endod 2010; 36(7):1122-9. https://doi.org/10.1016/j.joen.2010.03.040

[16] Rud J, Rud V, Munksgaard E. Periapical healing of mandibular molars after root-end sealing with dentine-bonded composite. Int Endod J 2001; 34(4):285-92. https://doi.org/10.1046/j.1365-2591.2001.00383.x 